\title{
THE IMPACT OF NATURA 2000 PROTECTED AREAS ON THE ECONOMIC DEVELOPMENT OF COMMUNITIES LOCATED WITHIN THE GREEN LUNGS OF POLAND (NORTH-EASTERN POLAND)
}

\author{
Antoni Mickiewicz ${ }^{1}$, Bartosz Mickiewicz², \\ ${ }^{1}$ Higher School of Agribusiness in Lomza; ${ }^{2}$ West Pomeranian University of Technology in Szczecin, \\ Faculty of Economics
}

\begin{abstract}
The paper presents possibilities of investments' realization in Nature 2000 areas in Poland and majors of Nature 2000 communes opinions about role of the network in socio-economic development of managed areas by them. It was focused on the presentation of legal possibilities of investment, by conducting analysis of conditions which potential investor is obeyed to fulfil in order to invest in those protected areas. Basing on typified to research communes with network Nature 2000, laid on area of Green Lungs of Poland, there were presented majors' opinions about restrictions and potential profits resulting from fact of Nature 2000 area possessing. It was underlined that most of inquired majors had declared that Nature 2000 areas in analysed communes had had limitations for inflow of investments and almost all of them had posited necessity of allocation of additional financial means by state budget in order to compensate for the effects resulting from Nature 2000 functioning in their areas.
\end{abstract}

Keywords: Nature 2000, investments, socio-economic development, Green Lungs of Poland. JEL code: Q18

\section{Introduction}

Adopted in 1992, the Council Directive on the conservation of natural habitats and of wild fauna and flora (the Habitats Directive) was aimed to promote the maintenance of biodiversity, taking into consideration the economic, social, cultural and regional requirements. It is generally regarded as the cornerstone of nature conservation policy, and together with the Birds Directive it established the broad network of Natura 2000 protected areas to safeguard against potentially damaging developments. Thus, nature conservation is founded on two pillars: the Natura 2000 network and the system of strict protection of species. Overall, the directive extends protection to more than 1,. 00 of plant and animal species, as well as more than 200 so-called habitats (e.g. special types of forests, meadows, wetlands, bogs). The Birds and Habitats Directives have had to evolve to reflect the successive enlargements of the European Union, which led to the adoption of subsequent regulations (Coffey, Richartz 2003).

The objective of the EU Biodiversity Strategy has been to halt the loss of biodiversity and ecosystem services, as well as to aid in stopping biodiversity loss by 2020 . It reflects the commitments made by the EU in 2010 within the framework of the international Convention on Biological Diversity. The Natura 2000 network is not a system of strict nature reserves, which would exclude all human activity. While it covers nature reserves under strict protection, most of the land remains in private hands. The approach to the protection and sustainable use of Natura 2000 sites is much broader and largely centred on people working with nature, rather than against it. However, it is up to the Member States to ensure that these areas are managed in a sustainable way, both ecologically and economically (Mehtata, Vuorisalo 2007).

One of such areas, unique on a European scale, is a region referred to as the Green Lungs of Poland (Zielone Pluca Polski, ZPP), which covers $63.235 \mathrm{~km}^{2}$ - i.e. about $20 \%$ of the country's territory. It is located in the north-eastern part of the country, covering the areas of WarminskoMazurskie and Podlaskie voivodeships, as well as parts of Mazowieckie, Kujawsko-Pomorskie and Pomorskie voivodeships. In the era of ever-present globalisation and progressing homogenisation, areas of unique character, in terms of both natural and cultural environment, are becoming 
increasingly important. The Green Lungs of Poland are definitely one such area. Its uniqueness is a value in and of itself, which needs to be protected, but also skilfully harnessed for the purposes of regional and local marketing. Many different forms of nature conservation are employed in the Green Lungs of Poland, for instance, there are 4 national parks, including Poland's largest Biebrza National Park, 243 nature reserves and 13 landscape parks (Kowalik 2006).

Protection under the Natura 2000 framework does not preclude economic use of land. Under the law, no particular restrictive or prescriptive regulations are made for Natura 2000 sites, unlike in the case of other forms of nature conservation, e.g. national parks. Protection of Natura 2000 sites involves primarily avoiding any actions which might significantly deteriorate the condition of natural habitats or habitats of plant and animal species, or significantly disturb the species for which a given Natura 2000 site has been designated. Each plan or project which may significantly interfere with the valuable sites included in the network must be subject to an assessment of impact on the conservation objectives and targets, as well as on the integrity of the site. Approval for actions which may adversely affect the site may be given only in strictly limited cases and on condition that the adverse effects are compensated for elsewhere, so that the conservation objectives and coherence of the network are maintained (Czochanski 2008).

\section{Issues, purpose and scope of the study}

People living in rural areas often tend to treat the Natura 2000 programme as an obstacle to socio-economic growth, mainly due to the restrictions on investments. It is generally believed that the establishment of "nature conservation areas" in a given community brings with it more negative than positive phenomena, including but not limited to:

- imposing extensive farming practices with regard to land and livestock and limiting the freedom of administering real estate;

- restricting or preventing business activities, both in terms of new investments and the expansion of existing enterprises;

- increasing the cost of new projects, e.g. related to road, energy, transmission infrastructure, through the necessity to implement various environmental safeguards;

- potential conflict with plans to develop tourism and leisure, e.g. collision of the river remediation programmes for tourism purposes with the requirements of the Natura 2000 framework;

- potential local conflicts due to compensatory claims proceedings (Mickiewicz, Mickiewicz 2016).

The objective of this study was to analyse the social understanding of the objectives of conservation areas and their impact on the economic potential of communities located within the "Green Lungs of Poland", as perceived by the representatives of local authorities. The research was carried out by the author himself in 2017 in 33 communities within the framework of a research programme implemented at the West Pomeranian University of Technology under the name "Socioeconomic factors of the sustainable development of rural areas covered by the Natura 2000 network within the Green Lungs of Poland". In the course of the study, the questionnaire survey was the primary research method for collecting factual data. Supplementary methods employed interviews and direct observation, allowing for a more thorough exploration of research problems and yielding additional data, as well as review of research papers on the subject published in recent years in Poland and abroad. 


\section{Results and discussion}

The fundamental question addressed by the study was how the Natura 2000 network affects the way communities function. Findings point to significant diversity. The establishment of this form of nature conservation, which took place in the communities included in the analysis in 2004-2015, was perceived as having both positive and negative aspects in 10 affected communities. In 13 communities, the perception of the network was unequivocally negative, while the remaining 10 did not observe any changes.

According to the heads of 19 communities included in the analysis, the fact that all or part of the area under their administration was included into the Natura 2000 network did not affect their financial situation. It should be noted, however, that the remaining 14 communities observed unfavourable phenomena related to the establishment of the new form of nature conservation. Community leaders listed among them: impeding economic growth (6 communities), declining interest in the purchase of land, declining industrial construction, reduced number of investments financed with the EU funds and mass withdrawal of investors (named by 2 communities each).

In connection with the above, the respondents were asked if their community should obtain additional financial resources to compensate for the losses (Fig. 1). The results show that only two community heads thought their communities should not be allocated any additional funds in compensation. The others (31 community heads and mayors) were of the opinion that such funds should be allocated, most of all for investments related to environmental protection. These included notably the construction of wastewater treatment plants and upgrading boiler stations (10 responses), obtaining alternative sources of energy (10 responses) and upgrading tourism infrastructure (11 responses). Nearly half of the respondents thought that additional funds should be allocated to the promotion of the community. Community representatives also believed it was essential to invest in upgrading road infrastructure (4 responses).

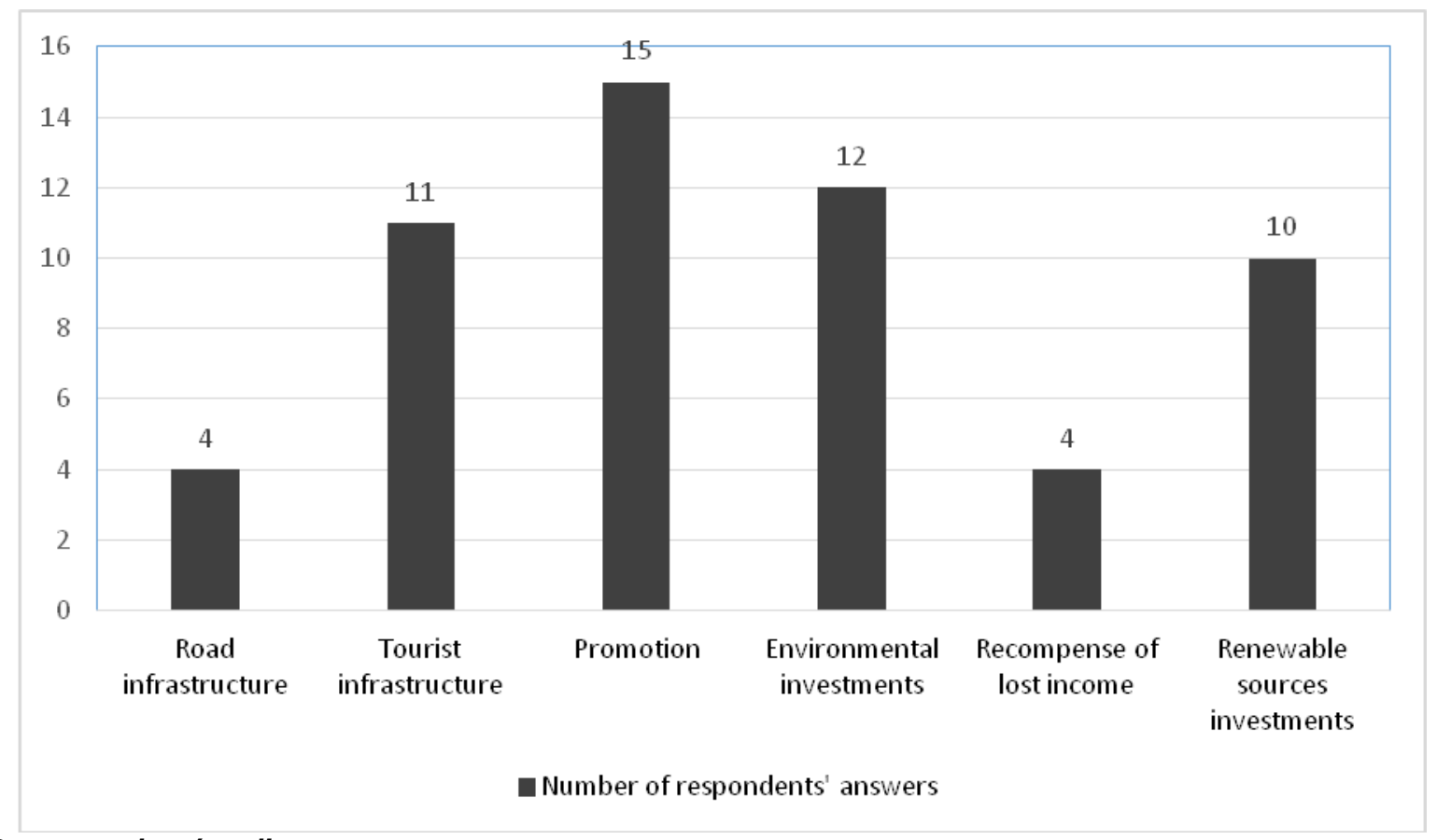

Source: authors' studies

Fig. 1. Spheres in which compensations for communes should be given because of their location in Nature 2000 areas 
Interestingly, communities often assume hypothetically that investors back out due to concerns over the complicated procedures related to the location of the project within a Natura 2000 site. At the same time, they fail to objectively account for other reasons, such as, to name one, the absence of spatial development plans for sites of interest for the investors in the community.

A considerable percentage of local governments ( 22 communities) get involved in measures aimed at educating the local residents on issues central to the functioning of this form of protection. Most commonly, these measures involve meetings of local authorities with residents. This is particularly true of communities in which pro-environmental organisations are active. Still, it is worrying that nearly one third of community leaders declared they were not interested in information campaigns related to the Natura 2000 scheme. In such areas, residents are left to far from reliable sources to learn about protected areas. The prevailing opinion there is that nature conservation on such a scale is an "invention of Brussels bureaucrats", "harmful to the region", "a lot of nonsense, which is incompatible with the local reality" (Mickiewicz, Gotkiewicz, 2009).

As mentioned above, some local government representatives were able to perceive some positive aspects of being part of a Natura 2000 site. The advantages listed by the respondents included: improving the condition of the natural environment (18 communities), development of rural tourism (17 communities) and organic farming (10 communities). According to the representatives of local authorities (12 communities), greater environmental awareness among the residents was also important. To a lesser extent, the respondents mentioned easier access to external sources of financing (4 communities) and introduction of environment-friendly technologies in business (Fig. 2).

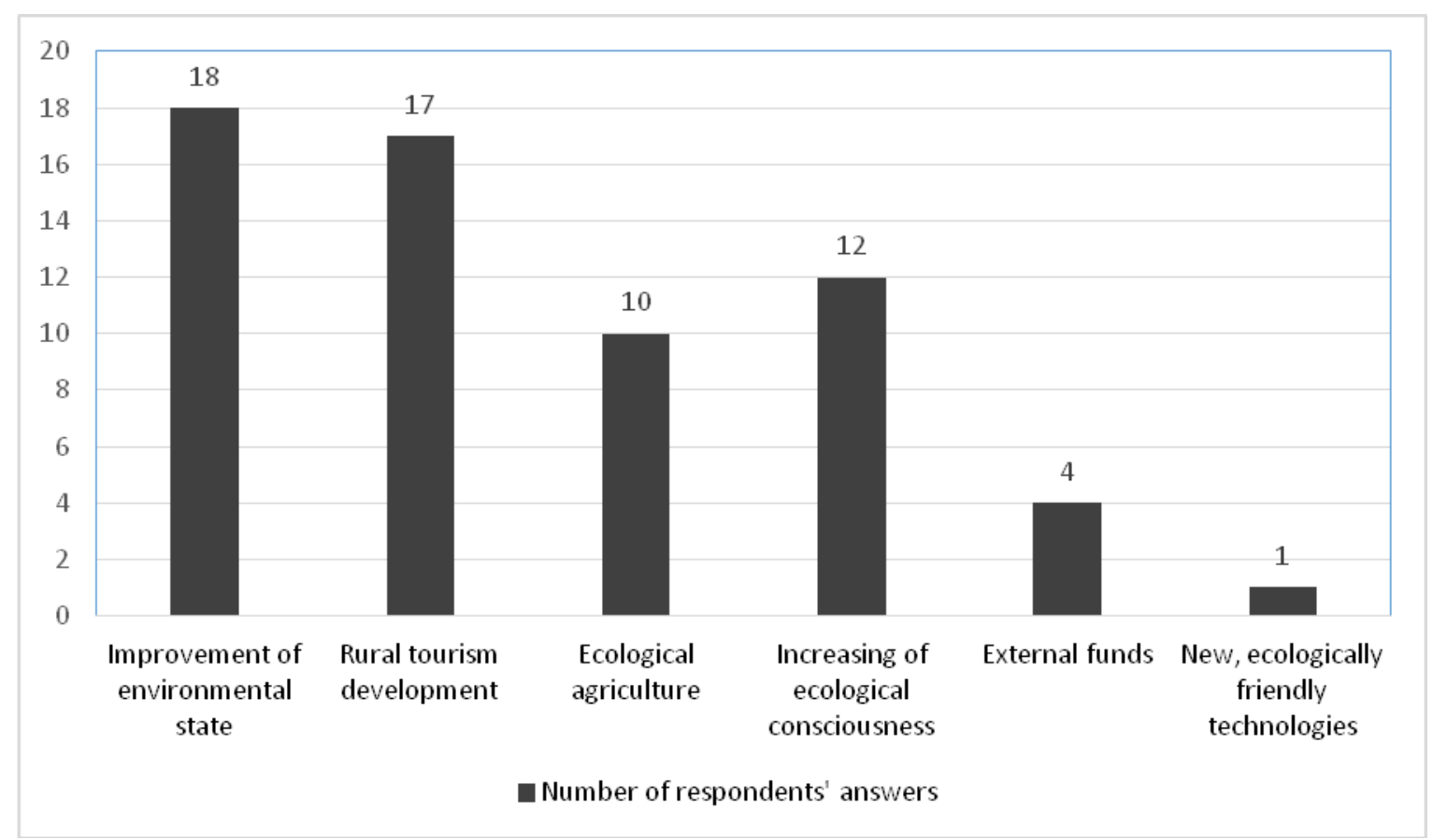

Source: authors' studies

Fig. 2. Positive aspects of introducing Nature $\mathbf{2 0 0 0}$ areas into communes

Negative factors affecting the socio-economic situation in the community were mentioned far more often. Representatives of local authorities noted difficulties and delays in planning and implementing public investments (22 communities) and the necessity to adjust or reduce the size of investment sites (20 communities). Further unfavourable factors included: withdrawal of 
potential investors (12 communities), necessity to reduce the scale of operations or change business profile ( 8 communities), lack of compensation for lost gains (5 communities) and prolonging administrative procedures ( 2 communities). Respondents also emphasised restrictions on agricultural activities (9) and exacerbation of social conflicts over environmental protection (17 responses) (Fig. 3).

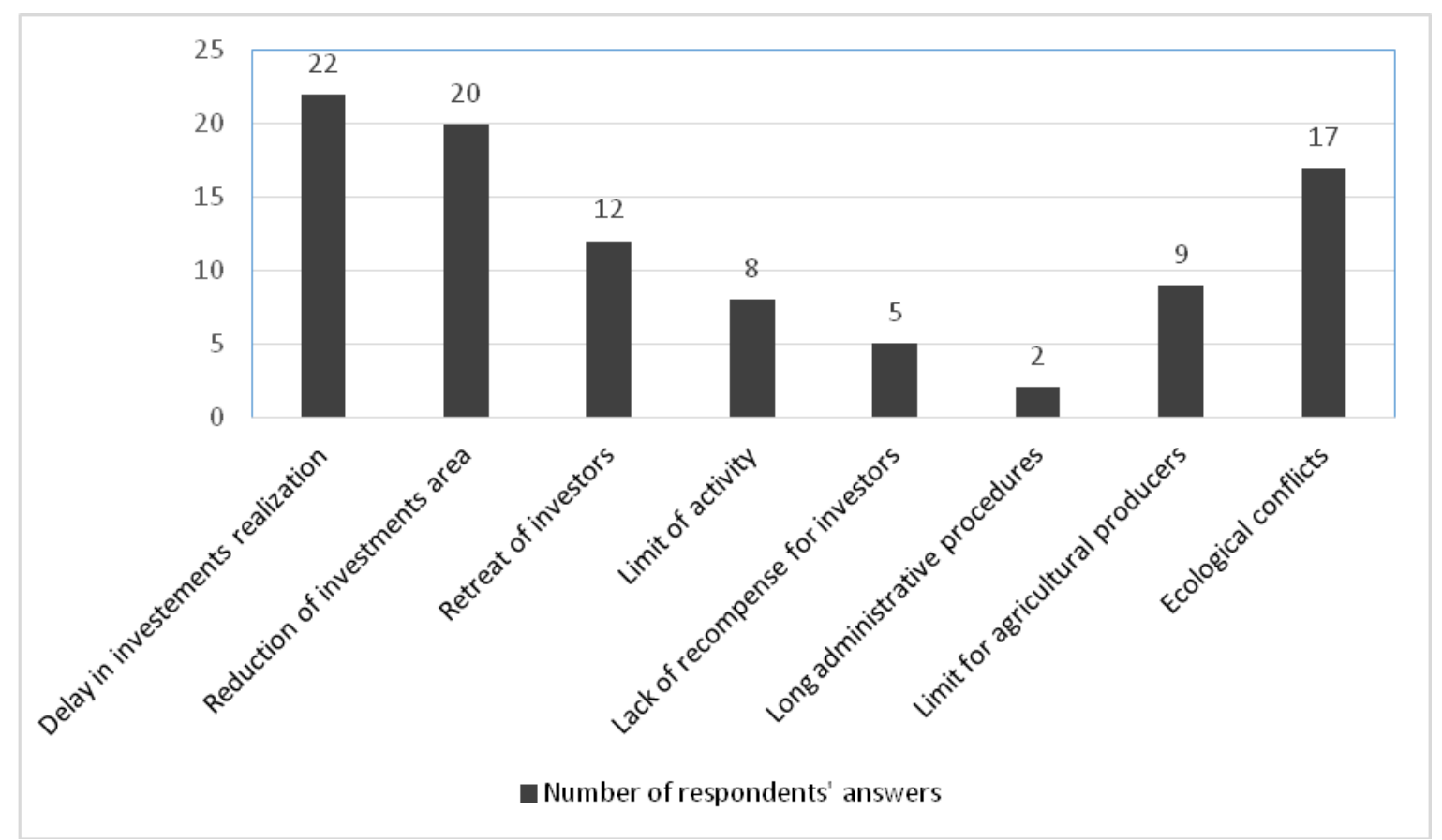

Source: authors' studies

Fig. 3. Negative aspects of Nature $\mathbf{2 0 0 0}$ areas introduced into communes

The last issue addressed in this part of the study concerned the impact of the Natura 2000 network on the two largest occupational groups active in the communities - farmers and rural entrepreneurs. In the case of the former, 12 community heads were not able to provide a straightforward answer whether the new form of environmental protection had an impact on farming activities. The rest assessed the impact of the network as negative (10 respondents), or less often as positive (9). It should be noted that only 2 community heads declared that Natura 2000 is of no relevance for farmers. Turning to the impact of Natura 2000 sites on the businesses operating within the community, 10 local government representatives declared that the presence of protected areas had a positive impact, however, this applied only to businesses from the tourism sector. The others viewed the impact as negative (12 responses) or neutral (11).

\section{Conclusions}

The establishment of Natura 2000 sites was an important undertaking, particularly from the environmentalist point of view. It provided a guarantee that natural habitats and valuable natural resources will be maintained. It is commonly believed, however, that this form of nature conservation has a negative impact on social and economic development of rural areas. This study shows that such an opinion is not fully justified, even in communities where a significant percentage of land was placed under protection. The present findings reveal that only one third of local government representatives observed negative consequences of the Natura 2000 scheme on the development of areas under their administration. In the remaining communities, the network was perceived to have a neutral or positive impact. The same applies to the impact of 
Natura 2000 on the functioning of two most numerous occupational groups in rural areas (farmers and owners of small and medium-sized enterprises). Thus, one might venture a conclusion that the negative impact of Natura 2000 on local communities should be regarded in the context of individual, specific cases, rather than as a general trend. In some cases, there is also an impression that the legal protection of Natura 2000 sites serves as a convenient excuse for ineptitude or lack of own initiative in local governments themselves.

\section{Bibliography}

1. Coffey, C., Richartz, S. The EU Habitats Directive, Generating Strong Responses, Institute for European Environmental Policy (2013). Project Deliverable No. D 17, pp. 1-26

2. Czochanski, J. Obszary Europejskiej sieci ekologicznej NATURA 2000 w wojewodztwie pomorskim (Areas of European Ecological Network NATURE 2000 in Pomeranian province). Instytut Geografii. (2008). Uniwersytet Gdanski, pp. 129-137

3. Kowalik, T. Zielone Pluca Polski: dobre skutki w ciaggu23 lat (Green Lungs of Poland: good effects after 23 years). Aura. (2016), nr 8, pp. 7-9

4. Mehtata, J., Vuorisalo, T. Conservation Policy and the EU Habitats Directive: Favourable Conservation Status as a Measure of Conservation Success. Environmental Policy and Governance (2007). Volume 17, Issue 6, pp. 363-375zMickiewicz B., Gotkiewicz W. Analiza strategii rozwoju wybranych gmin objetych siecia "NATURA 2000" polozonych na terenie Zielonych Płuc Polski (Analyses of chosen communes development strategies with NATURE 2000 lied on the area of Green Lungs of Poland). Zachodniopomorski Uniwersytet Technologiczny w Szczecinie (2009), pp. 131-140 